\title{
Weakness associated with the pathological presence of lipid in skeletal muscle: a detailed study of a patient with carnitine deficiency
}

\author{
H. ISAACS, J. J. A. HEFFRON ${ }^{1}$, MARGARET BADENHORST, \\ AND AVONNE PICKERING \\ From the Neuromuscular Research Laboratory, Department of Physiology and Department of \\ Physiological Chemistry, Medical School, University of Witwatersrand, Johannesburg, \\ S. Africa
}

SYNOPSIS A patient with muscular weakness demonstrating pathological lipid accumulation and abnormal mitochondria in skeletal muscle has been studied. The lipid accumulation and mitochondrial changes are thought to be related to the established deficiency of carnitine in this patient's muscle. Theo symptoms of muscular weakness associated with lipid accumulation in the skeletal muscle in then absence of complaint of muscle cramps or myoglobinuria are thought to be diagnostic of carnitine deficiency. The failure of the sarcoplasmic reticulum to accumulate $\mathrm{Ca}^{2+}$ is discussed. The patient' strength responded dramatically when propranolol was added to his steroid therapy.

The pathological presence of lipid in muscle fibres was first described by Bradley et al. (1969). In 1970 Engel et al. described muscle cramp in the muscle of identical twins who had myoglobinuria and postulated a defect in long-chain fatty acid metabolism. In the editorial of the same journal, Bressler (1970) suggested that the pathology was a deficiency of either carnitine or carnitine palmityl transferase 1 or 11. Subsequently, Engel and Angelini (1973) described a new syndrome of carnitine deficiency as the basis of a lipid storage myopathy which was further elucidated by Karpati et al. (1974). Di Mauro and Di Mauro (1973) described a muscle disease associated with myoglobinuria due to carnitine palmityltransferase deficiency in a patient who had similar symptoms to the twins described by Engel et al. (1970). Van Dyk et al. (1975) described the myopathy of an 8 year old boy with carnitine deficiency who also had cardiac involvement. Because of the rarity of the condition, we now report a further case of muscle carnitine deficiency associated with lipid storage myopathy in which the serum carnitine was only slightly decreased.

\footnotetext{
' Present address: Department of Anesthesiology, Mayo Clinic, Rochester, Minnesota 55901, USA.

(Accepted 7 July 1976.)
}

CASE REPORT

A 20 year old Swiss brick-layer (Fig. 1) presented with a history of progressive weakness over the previous two years. At the time of admission to hospital he was able to walk only 100 yards on level ground and had great difficulty in climbing stairs. He had been forced to give up his work three months earlier as he found it impossible to keep lifting the bricks. He had also noted a weight loss of approximately $12 \mathrm{~kg}$ over the past 10 months. There was no complaint of muscular pain, or of any sensory disturbance. There was no family history of any muscular weakness as far as he was aware.

On examination he was found incidentally to have scabies. His blood pressure was $125 / 60 \mathrm{mmHg}$ in the horizontal position. Pulse rate was $88 / \mathrm{min}$, regular, and of good volume. He had generalised muscular wasting and weakness which was most marked in the proximal muscles. He was unable to rise from the sitting position without help and tended to drag his feet as he walked.

Investigations, which included chest radiograph, electrocardiogram, full blood count, serum urea and electrolytes, erythrocyte sedimentation rate, serum proteins, immunoglobulins, antiruclear factor, rheumatoid factor and Kolmer test, were all normal or negative. 


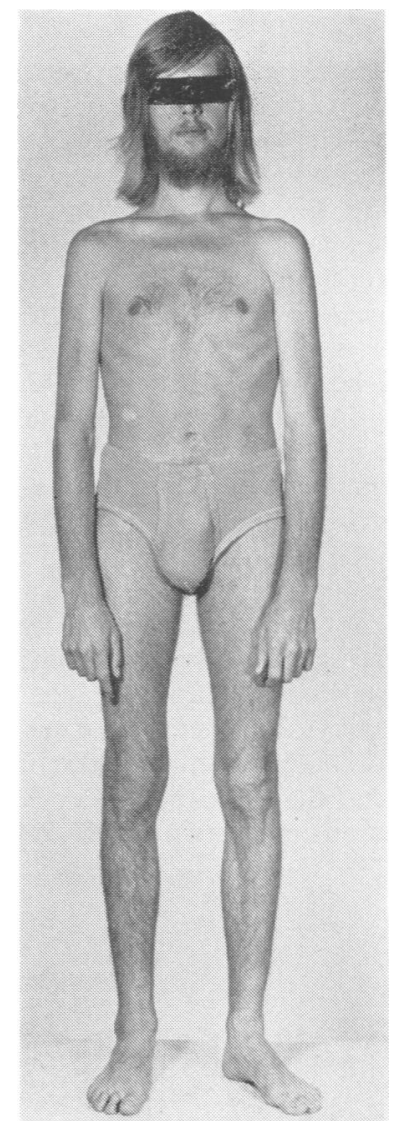

FIG. 1 There is no evidence of wasting of any particular muscle group.

Gastrointestinal screening tests for malabsorption studying serum carotene, Vitamin B12, folic acid, iron, and a 72 hour collection of stool for fat excretion were normal.

The total serum cholesterol level was $4.95 \mathrm{mmol} / \mathrm{l}$, triglycerides $99.0 \mathrm{mg} / \mathrm{l}$, total lipid $6.40 \mathrm{~g} / \mathrm{l}$, phospholipid $2.5 \mathrm{~g} / \mathrm{l}$, cholesterol esters, total esters, total fatty acids, beta lipoproteins, beta cholesterol, and low density lipoproteins were normal. The naked eye appearance of the serum was clear. The serum aspartate transaminase was elevated to $96 \mathrm{IU} / 1$ (normal 2-35). The lactic dehydrogenase level was 251 IU/1 (normal 90-200), creatine phosphokinase (CPK) 335 IU/l (normal 0-50) and aldolase $43 \mathrm{IU} / 1$ (normal 5-31). The prothrombin index was $100 \%$. A glucose tolerance curve was normal. On fasting he developed ketonuria normally and the serum ketone level after 24 hours was $100 \mathrm{mg} / \mathrm{l}$. Plasma cortisol showed a normal diurnal fluctuation. A rectal mucosal biopsy was performed and this was found to be normal with specific attention paid to triglyceride deposition.

Electromyography was carried out using concentric needle electrodes. There was no evidence of spontaneous activity. On volition the motor unit activity developed normally, but full recruitment was not obtained in the weaker muscles and the motor unit potentials tended to be of low voltage. On isometric contraction the motor unit potentials were seen to widen readily with early fatigue, as seen with weakness of myopathic origin. Nerve conduction studies, both motor and sensory, were carried out on both upper and lower limbs and these were found to be normal.

A biopsy of the left deltoid and subsequently the left quadriceps femoris muscle was carried out under local anaesthesia.

\section{METHODS}

Muscle tissue was removed from the patient under local anaesthesia and the specimen for histology and histochemical analysis was maintained at resting length by securing the specimen at each end with a cat-gut suture stretched over a wooden spatula. After half an hour the muscle was sectioned, mounted on chucks, and the specimen held in position by gum tragacanth for both transverse and longitudinal sectioning. The muscle was then cooled to $-160^{\circ} \mathrm{C}$ in liquid isopentane which had previously been cooled in liquid nitrogen. Sections $10 \mu \mathrm{m}$ thick were cut on a cryostat and stained with haematoxylin and eosin ( $\mathrm{H}$ and E), periodic acid-Schiff (PAS), a modified trichrome stain, and oil red 0 . The histochemical processing included phosphorylase, NAD diaphorase, succinic dehydrogenase, myosin ATPase at pH 9.4,4.3, and 4.6., and, after previous treatment with EDTA, at $\mathrm{pH} 4.5$.

At the time of biopsy, sections were taken for electronmicroscopy. These were fixed in cold gluteraldehyde buffer and post-fixed in cacodylate-buffered $5 \%$ osmium tetroxide. After dehydrating with alcohol the sections were embedded in Epon/Araldite. Thin sections were cut and stained with uranyl acetate and lead citrate and viewed with a Siemens electronmicroscope.

A further muscle specimen was homogenised in 9 volumes of $0.3 \mathrm{M}$ sucrose- $20 \mathrm{mM}$ imidazole, $\mathrm{pH} 6.85$ with an all-glass hand homogeniser at $2^{\circ} \mathrm{C}$. Sarcoplasmic reticulum (SR) was isolated by centrifuging the post-mitochondrial supernatant at $200000 \mathrm{~g}$ for 60 minutes.

Myosin ATPase activity and calcium uptake studies were made immediately after preparation of SR according to methods previously described by us 
(Isaacs and Heffron, 1974). The protein content of the SR was estimated by the method of Lowry et al. (1951).

The specimens of muscle for carnitine analysis were frozen immediately in liquid nitrogen and stored at $-30^{\circ} \mathrm{C}$. The analysis of carnitine in serum and muscle was carried out with the enzymatic method of Pearson et al. (1969). Serum was obtained from venous blood and immediately deproteinised with an equal volume of $0.6 \mathrm{M} \mathrm{HClO}_{4}$. Precipitated protein was removed by centrifugation and the supernatant neutralised with saturated $\mathrm{K}_{2} \mathrm{CO}_{3}$. The perchlorate precipitate was removed by centrifugation and $0.2 \mathrm{ml}$ aliquots were used for carnitine assay. Control serum was obtained from five normal volunteers. Deltoid and quadriceps muscle specimens from the patient, and quadriceps specimens from six normal individuals were analysed for carnitine content. The specimens were extracted with five volumes of $0.6 \mathrm{M}$ $\mathrm{HClO}_{4}$. Protein-free supernatants were prepared as described above for serum. $0.2 \mathrm{ml}$ deproteinised serum or $0.02 \mathrm{ml}$ muscle extract was analysed in a final volume of $1.0 \mathrm{ml}$ of the assay medium as described by Pearson et al. (1969).

\section{RESULTS}

The size of the muscle fibres varied between 30 and 90 $\mu \mathrm{m}$. There was no increase in connective tissue or fat between the fibres. The blood vessels encountered appeared to be healthy and there was no inflammatory infiltrate. With the modified trichrome stain, numerous small vacuoles were seen to be present in a large number of the fibres.

Histochemical study revealed that the abnormality affected the type 1 fibres (Fig. 2). The abnormal deposition was best seen with the NAD diaphorase (Figs. 3, 4) and succinic dehydrogenase preparations and the deposits stained well with oil red 0 (Fig. 5).

On electronmicroscopic study the muscle was found to be grossly abnormal and showed evidence of numerous lipid vacuoles (Fig. 6). These were so abundant that they were found in parallel rows and tended to disrupt the myofibrillar pattern. The mitochondria were particularly abnormal; many were swollen and showed fragmented cristae, while others contained paracrystalline substance in various stages of formation. The basement membrane was excessively folded and there was patchy evidence of myofibrillar depletion and blurring of the Z.-lines (Fig. 7)

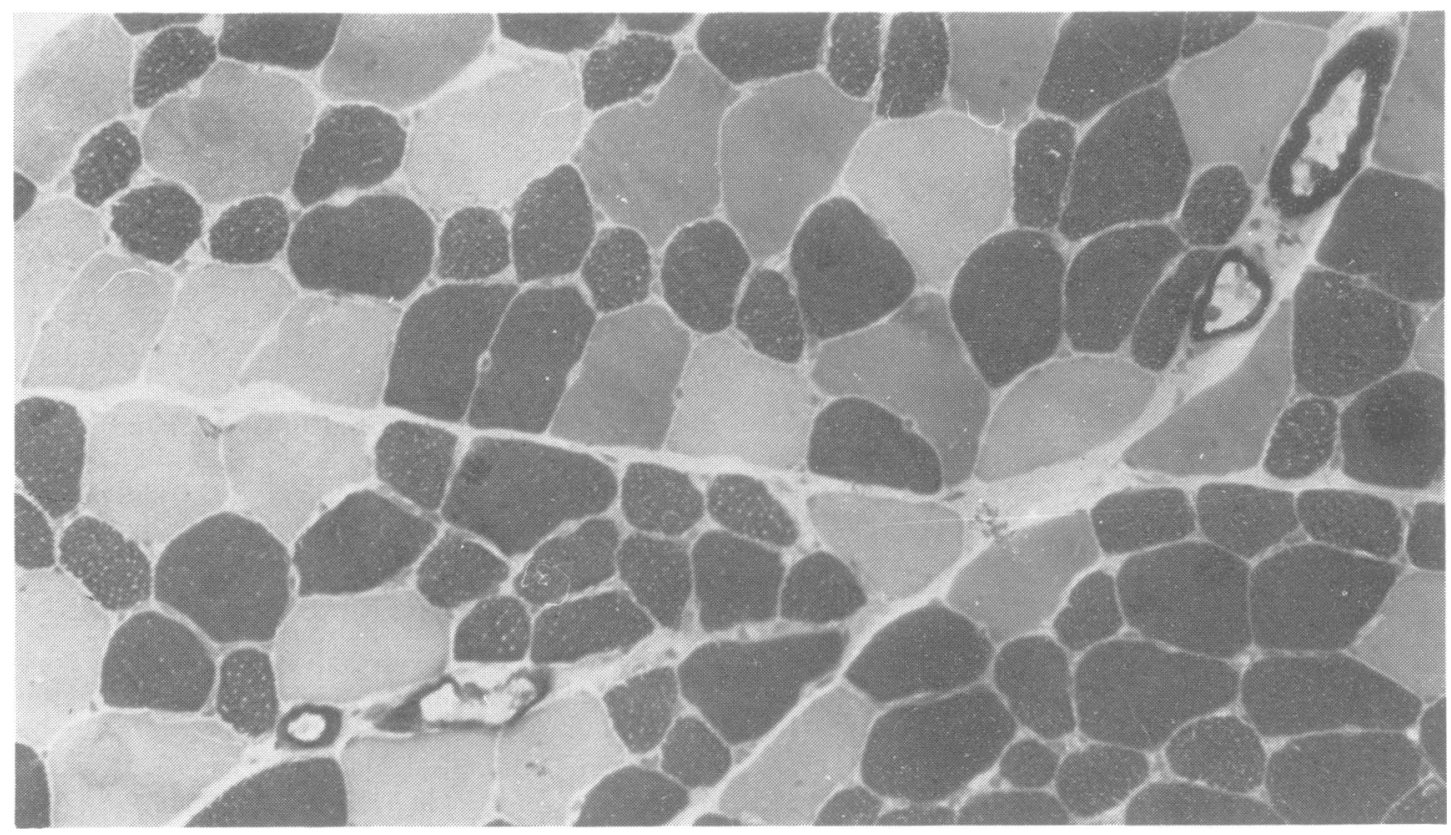

FIG. 2 Myosin ATPase preparation at pH 4.6, showing grouping of type 1 fibres and vacuolation best seen in the smaller of the type 1 fibres. $\times 80$. 


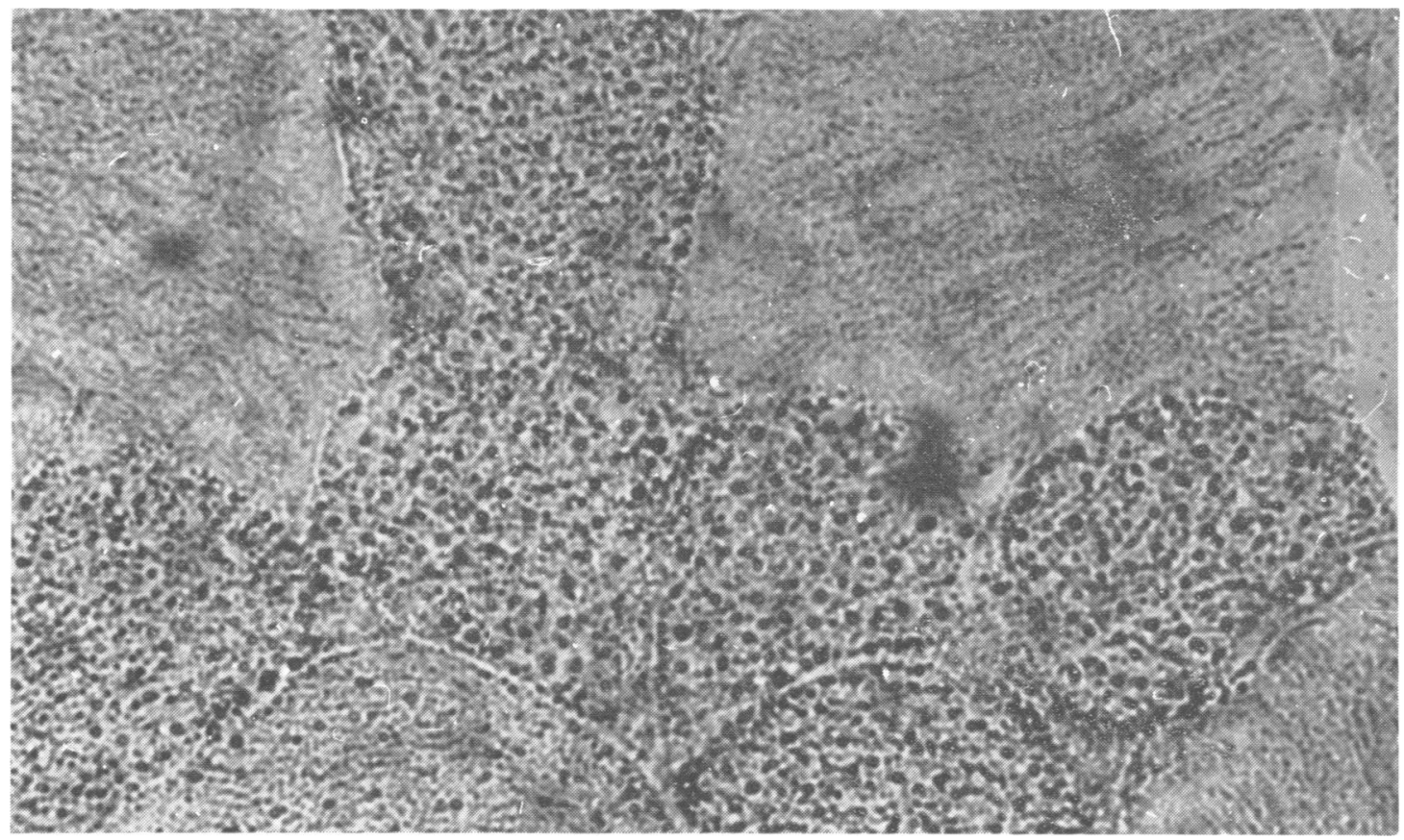

FIG. 3 NAD diaphorase preparation of muscle cut transversely, showing abnormality in the type 1 fibres. $\times 360$.

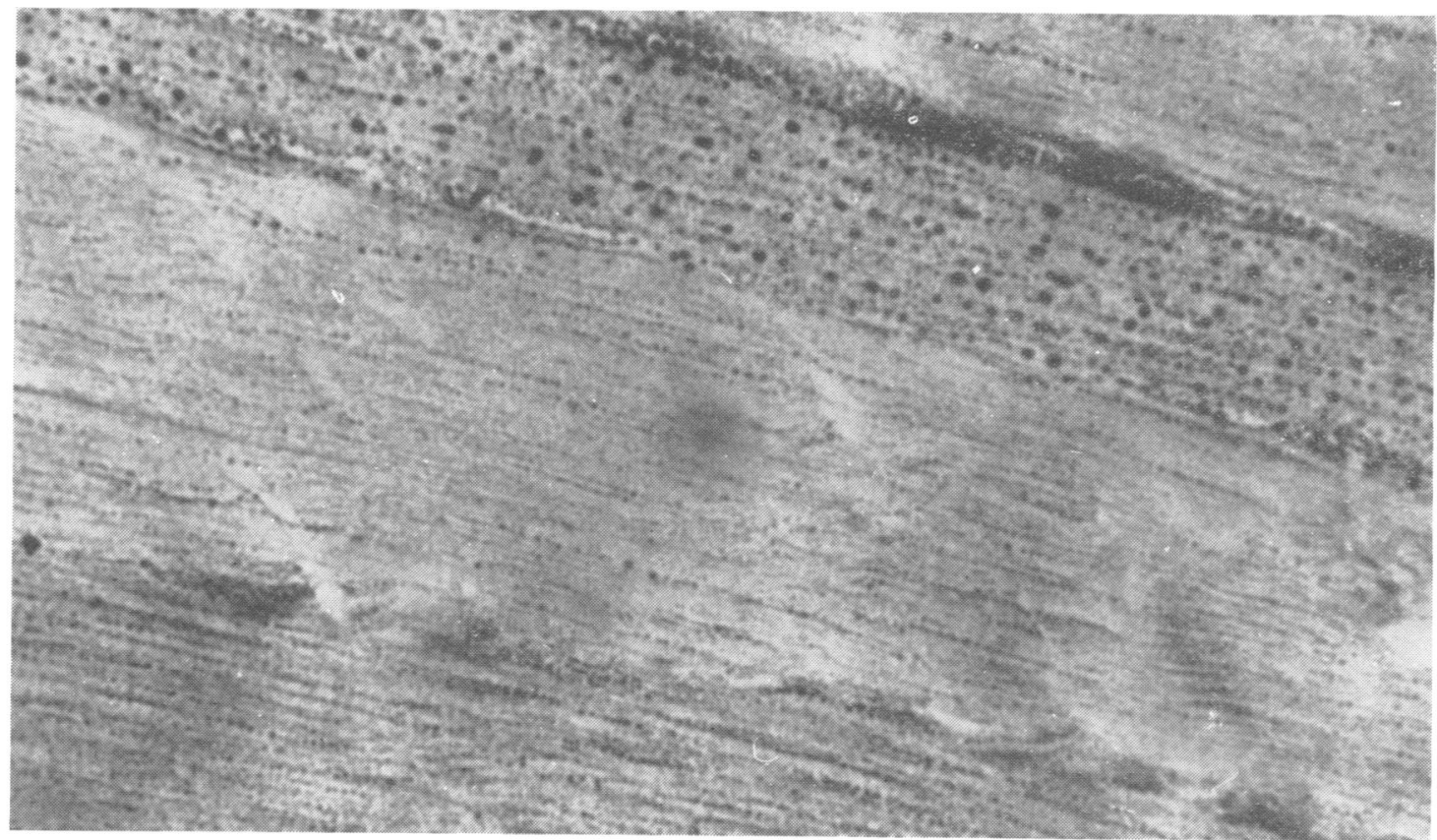

FIG. 4 NAD diaphorase preparation of muscle cut longitudinally, showing deposits in the affected type I fibres. $\times 360$. 


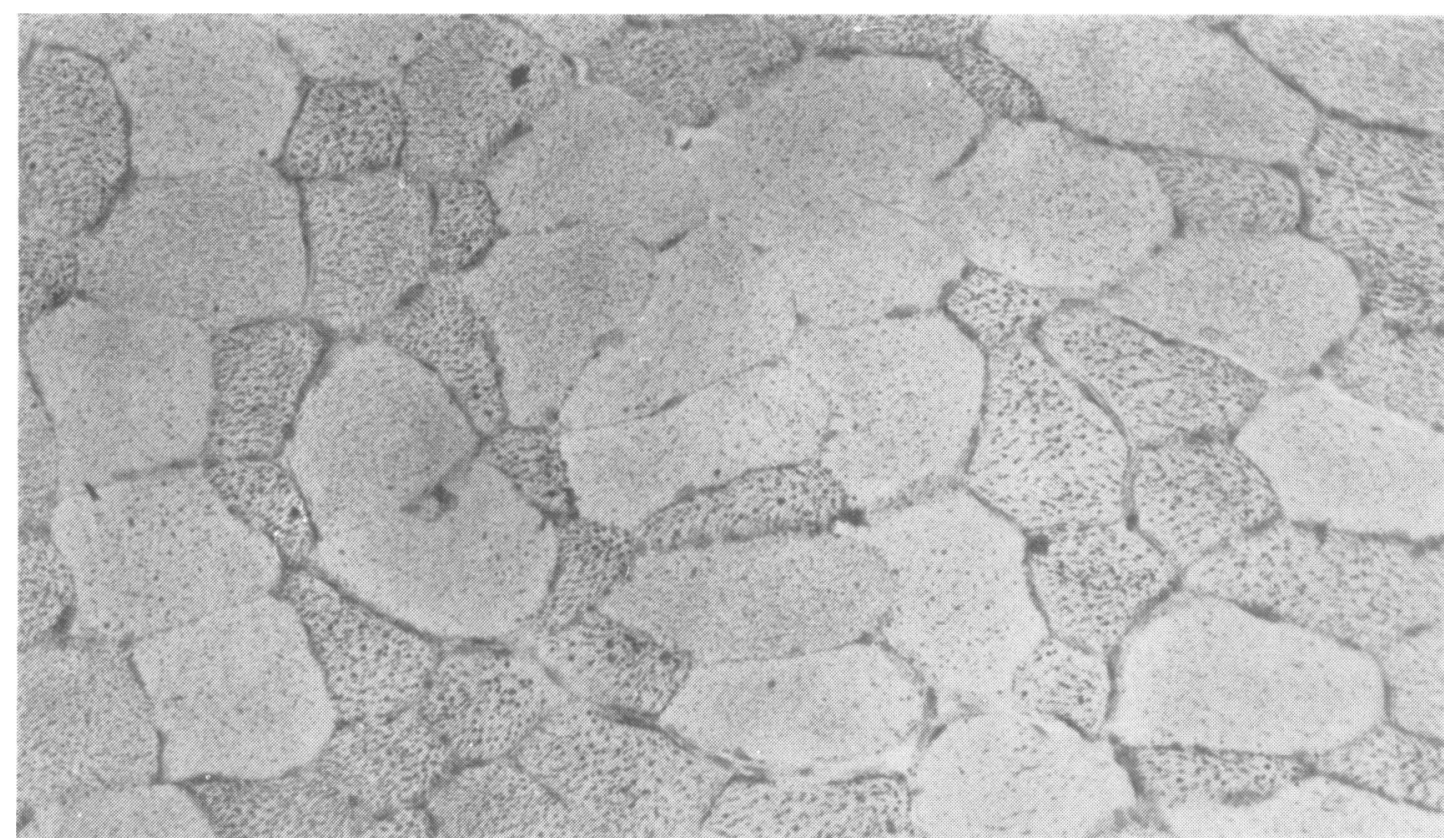

FIG. 5 Oil red 0 preparation showing lipid deposition in the type 1 fibres. $\times 80$.

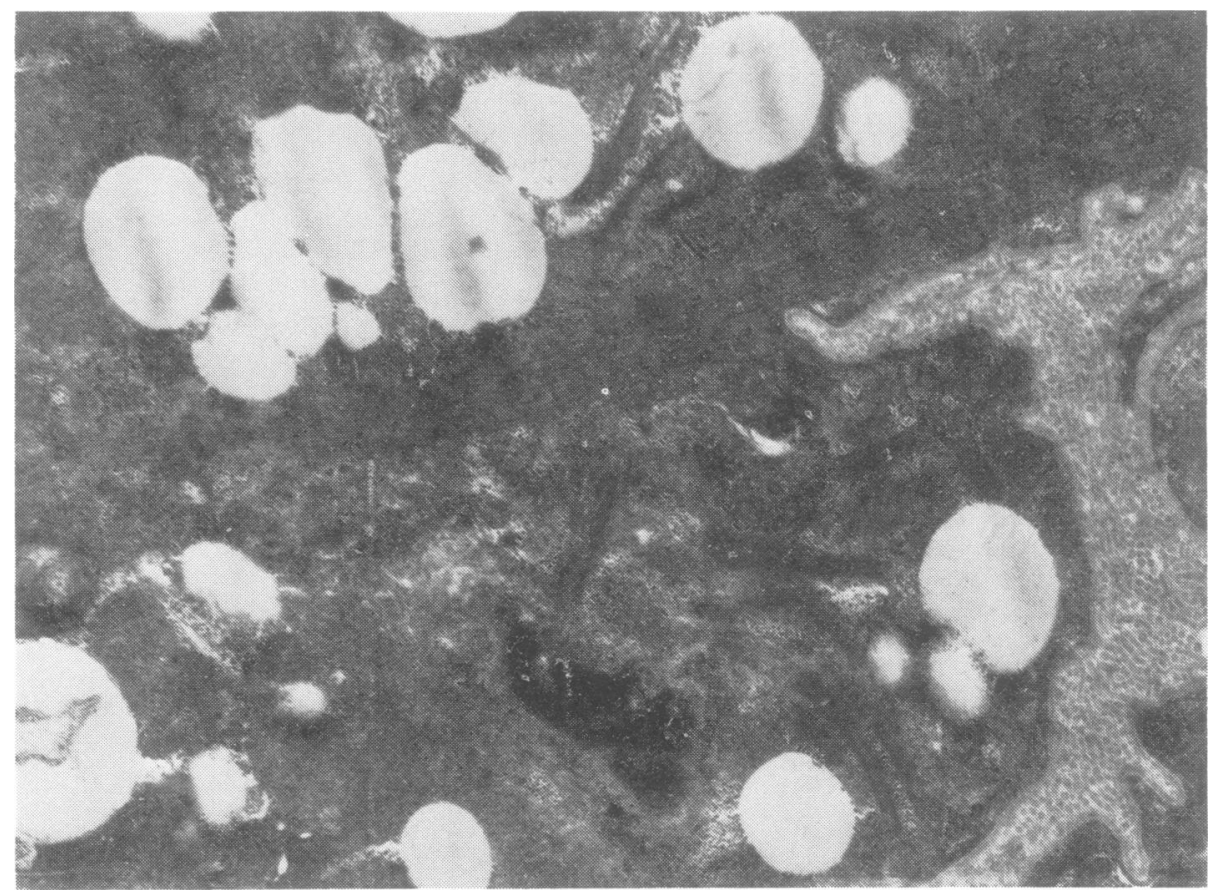

FIG. 6 Ultramicrograph showing excessive lipid, disruption of the myofilamentous pattern and folding of the basement membrane, and formation of curvilinear paracrystalline substance. $\times 8000$. 


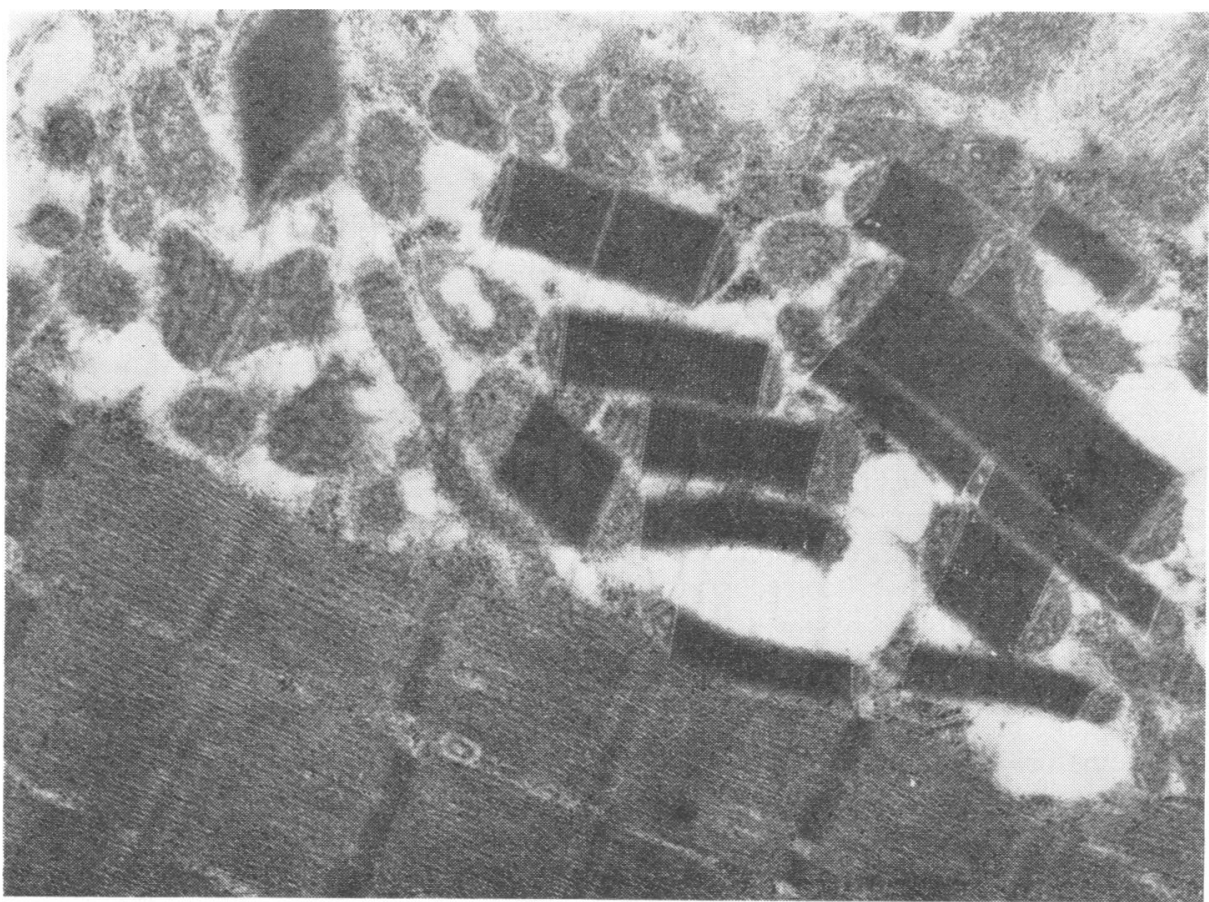

FIG. 7 Ultramicrograph showing abnormal mitochondria containing paracrystalline substance. Lipid deposition is excessive. $\times 10000$.

Carnitine levels in serum and skeletal muscle of the patient are compared with normal values in Table 1. Serum carnitine was only slightly less than the lower limit of the normal range. However, carnitine levels in two muscle samples from the patient were only $5 \%$ and $8 \%$ of the mean level in normal muscle.

The initial rate, total uptake of calcium, and $\mathrm{Ca}^{2+}-$ dependent ATPase activities of isolated sarcoplasmic reticulum from the patient and from five normal

T A B L E 1

SERUM AND MUSCLE CARNITINE LEVELS OF PATIENT AND NORMAL INDIVIDUALS

\begin{tabular}{lcl}
\hline & Normal & \multicolumn{1}{c}{ Patient } \\
\hline Serum & & \\
( $\mu \mathrm{mol} / \mathrm{l})$ & $54.9 \pm 2.3(5)$ & 46.6 \\
Muscle & $3.75 \pm 0.40(6)$ & 0.18 (quadriceps) \\
$(\mu \mathrm{mol} / \mathrm{g}$, wet weight) & & 0.29 (deltoid) \\
\hline
\end{tabular}

Normal levels are expressed as mean + SEM. Number of normal individuals in parenthesis. individuals are shown in Table 2. Both the rate of calcium uptake and $\mathrm{Ca}^{2+}$-dependent ATPase activity of the SR of the patient are within the respective normal ranges. Total calcium uptake by SR of the patient, however, was decreased by $52 \%$ compared with normal.

T A B L E 2

CALCIUM UPTAKE AND Ca ${ }^{2+}$-DEPENDENT ATPase ACTIVITY OF ISOLATED SARCOPLASMIC RETICULUM OF SKELETAL MUSCLE OF PATIENT AND NORMAL INDIVIDUALS

\begin{tabular}{lcc}
\hline & Normal & Patient \\
\hline Calcium uptake: & & \\
Rate $(\mu \mathrm{mol} / \mathrm{mg} / \mathrm{min})$ & $0.732 \pm 0.190$ & 0.739 \\
Total $(\mu \mathrm{mol} / \mathrm{mg})$ & $1.947 \pm 0.129$ & 0.927 \\
$\mathrm{C}^{2+}$-dependent ATPase : & $0.800: 0.037$ & 0.954 \\
$(\mu \mathrm{mol} / \mathrm{mg} / \mathrm{min})$ & & \\
\hline
\end{tabular}

Normal values are given as mean $\pm S E M, n=5$. Assay temperature was $37^{\circ} \mathrm{C}$. 


\section{DISCUSSION}

Carnitine (gamma-trimethyl anino-beta-hydroxybutyrate) is an essential cofactor involved in the transfer of fatty acids into mitochondria where they are oxidised by the process of beta-oxidation (Fritz and Yue, 1963; Newsholme and Start, 1973). Recently, it has been demonstiated by Pande (1975) that, while the mitochondrial inner membrane is not readily permeable to carnitine or its esters, it allows their transport by exchange diffusion facilitated by the presence of a carnitine acylcarnitine translocase in the inner membrane. Of mammalian tissues, skeletal and cardiac muscle have the highest levels of carnitine (Marquis and Fritz, 1965), while brain and liver have the least. In choline-deficient states, the liver is unable to synthesise carnitine and this results in muscle weakness, syncope, and epilepsy (Corredor et al., 1967). Carnitine synthesised in the liver is then transported to other tissues and, as the concentrations of carnitine in most tissues are several tirnes greater than in plasma, the uptake mechanism must be an active one, though the nature of the uptake mechanism is unknown. The muscle carnitine content is normally much higher than that of the serum (Di Mauro et al., 1973), thus the presence of normal serum level of carnitine in our patient and the very low muscle content, indicated a block in the passage of carnitine into the muscle, as in the case of Van Dyk et al. (1975). The presence of a normal serum level of carnitine and the absence of any biochemical evidence of metabolic dysfunction or clinical enlargement of the liver suggests that liver function is normal in this patient. The heart sounds were normal, there were no symptoms referable to the cardiovascular system, and this, together with the normal ECG, indicates that the heart at this stage is not seriously involved.

Although the rates of calcium uptake and $\mathrm{Ca}^{2+}$ dependent ATPase activity of the SR are known to be reduced in some myopathies, these properties of SR were normal in the present case. The large decrease in total calcium uptake by the SR of the patient may reflect a reduced capacity of the intact SR for calcium, but the significance of this finding in relation to the clinical symptoms is not clear. No mitochondrial studies were carried out and it would be of importance to know whether the mitochondria are capable of accumulating $\mathrm{Ca}^{2+}$. Such mitochondrial $\mathrm{Ca}^{2+}$ cumulative dysfunction occurs in Luft's disease where recycling of $\mathrm{Ca}^{2+}$ may take place in vivo (Di Mauroet al., 1975) and results in stimulation of respiration and uncoupling. There was, however, no evidence of abnormal heat production in this case and most of the mitochondrial changes appeared anatomically destructive. This, together with the myofibrillar changes associated with muscle weakness, is not a feature of Luft's disease.
Di Mauro (1976) suggests that in most instances the mitochondrial changes seen in so called mitochondrial myopathies are secondary to changes within the muscle itself. The mitochondrial changes in this patient are of interest as mitochondrial changes have been present in association with lipid accumulation in previously reported cases of carnitine deficiency. Of particular interest is the formation of an electrondense and paracrystalline substance in the mitochondria in this case, as it was also noted in the cases of myopathy associated with lipid storage described by Engel and Siekert (1972) and Bradley et al. (1972). It is possible that the changes induced in the mitochondria relate to the carnitine deficiency which leads to the accumulation of lipid within the muscle and, in some way, to structural change within

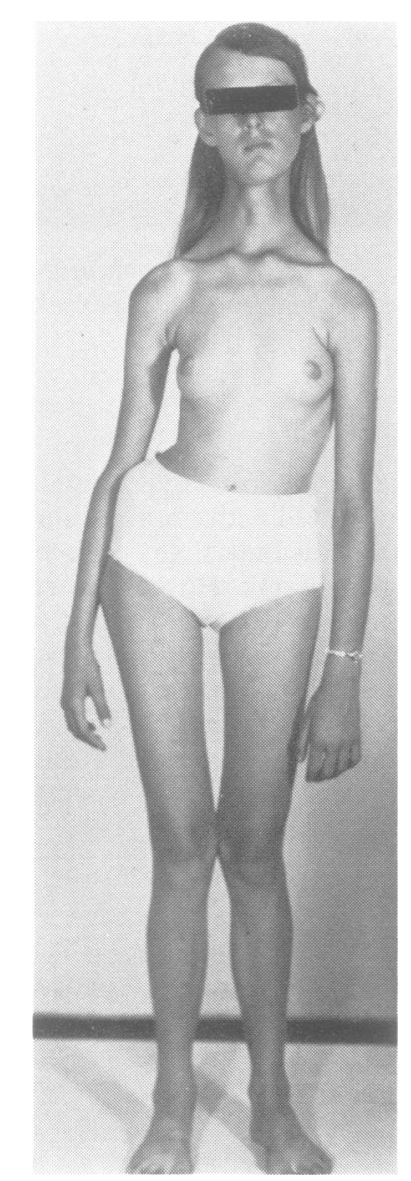

FIG. 8 Patient had generalised muscular weakness and kyphoscoliosis. 
the mitochondria. We believe the mitochondrial changes are, in fact, secondary to the carnitine deficiency and suggest that the deficiency itself, or mechanisms induced by such deficiency, may be one of the triggering mechanisms for the production of the paracrystalline substance seen in this and previous cases.

Many of the described defects in fatty acid metabolism manifest with symptoms apart from weakness, as in the cases with carnitine palmityltransferase deficiency (Di Mauro and Di Mauro, 1973), and the myoglobinuria and elevated triglycerides of the brothers described by Bank et al. (1975). One of us (H.I.) has encountered two cases, a brother and a sister, who presented with the identical symptoms described by Engel et al. (1970) and Di Mauro and Di Mauro (1973), these patients having each on different occasions presented with severe myoglobinuria and renal failure. They gave the typical history of muscular cramps associated with either fasting or exercise. Ischaemic work produced a normal rise in lactic acid and normal ketone production on starvation. There was no evidence of excessive lipid accumulation in the muscle similar to the case of $\mathrm{Di}$ Mauro and Di Mauro (1973), which differs from the case described by Engel et al. (1970) where lipid accumulation occurred. This may represent a difference between carnitine palmityltransferase I and II (Hoppel and Tomec, 1972). Unfortunately, muscle biochemical studies have not been carried out to date and the patients have refused further muscle biopsy, but on the present evidence they are identical to the case of palmityltransferase activity deficiency of $\mathrm{Di}$ Mauro and Di Mauro. The occurrence of lipid accumulation in muscle, weakness, and mitochondrial abnormalities, has previously been described by Shy et al. (1966), Engel and Dale (1968), Bradley et al. (1969), Engel (1970) and Isaacs and Muncke (1975). Neutral lipid may also be deposited in other tissues and Jordans (1953) described two brothers with progressive weakness where leucocytes and monocytes contained fat vacuoles. Leucocyte lipid storage has also been associated with ichthyosis, in which case the triglyceride deposition occurred in most tissues including muscle (Chanarin et al., 1975), but there was no evidence of muscle weakness.

Carnitine deficiency as a cause of weakness associated with lipid accumulation in muscle as described in our and previous cases, is unassociated with muscle pain, cramps, or myoglobinuria, a feature which may

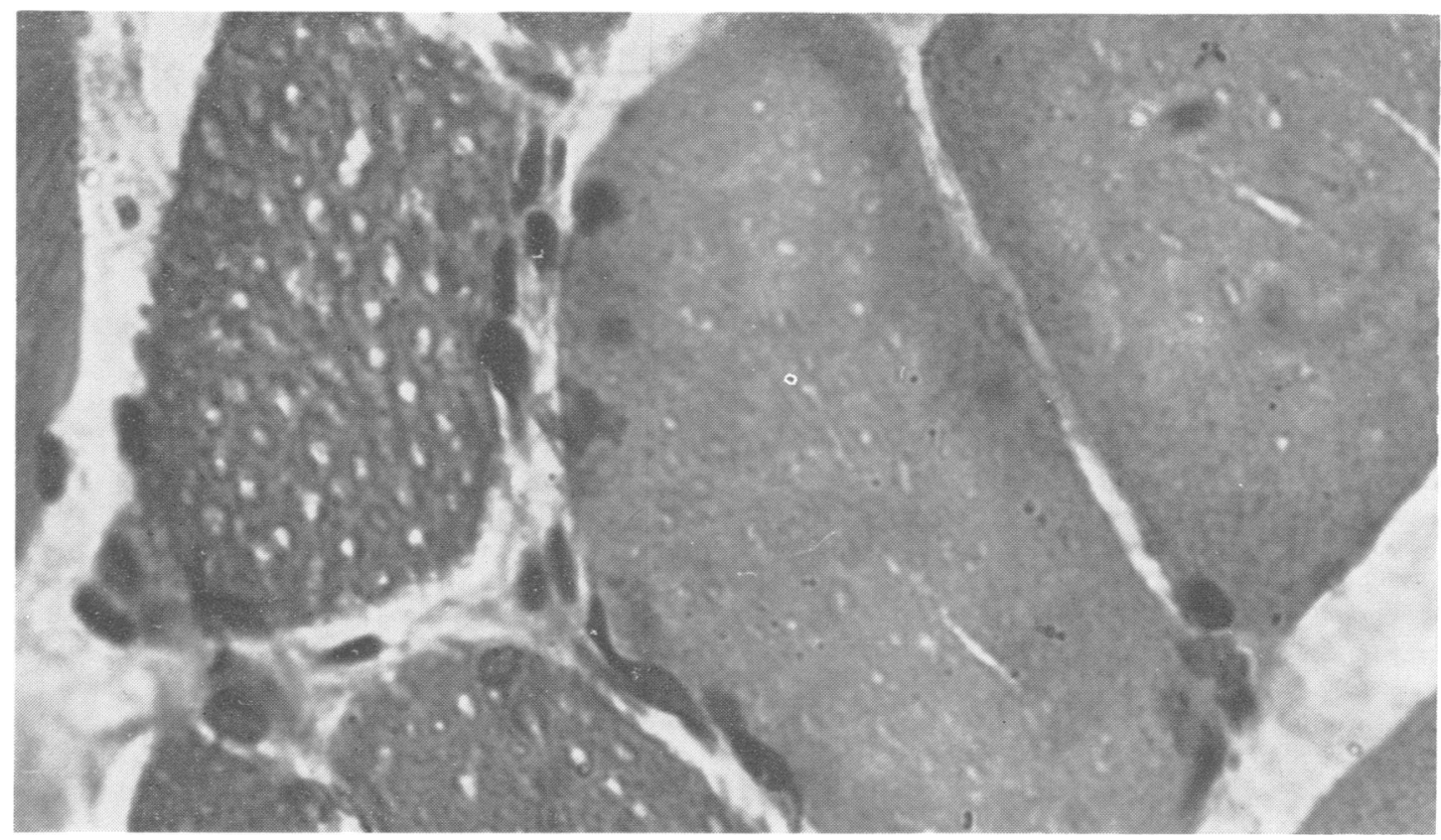

FIG. $9 H \&$ E preparation showing vacuolation in type 1 fibres which was established as triglyceride deposition. 
prove to be a pointer to this specific deficiency. $\mathrm{Re}$ duced carnitine content of muscle can also be asymptomatic and is obviously level dependent as in the parents of the case of carnitine deficiency described by Van Dyk et al. (1975).

In our particular case, there has been a dramatic response to therapy. Prednisone in a dose of $30 \mathrm{mg}$ daily was given for six months with only slight improvement. The prednisone was then reduced to 5 mg twice daily and propranolol $40 \mathrm{mg}$ three times daily was added over the subsequent three months. A dramatic overall improvement in muscular strength has occurred to the point where he has returned to work. This response is unexplained and this improvement may be fortuitous, as exemplified by a previous undocumented patient seen by Isaacs (Fig. 8) who, at the age of 12 years, demonstrated generalised weakness and moderate kyphoscoliosis. Biopsy showed muscle containing numerous fat deposits in the type 1 fibres (Fig. 9). Her strength gradually improved with the passage of time, though it never became normal. On the other hand, propranolol is known to release triglyceride from muscle and perhaps the chance combination of therapies has been effective. In time the steroid will be withdrawn and the propranolol continued on its own. It is hoped to repeat the carnitine estimation at a later stage.

This work was made possible by grants from the South African Medical Research Council, the Faculty of Medicine Senate Research Fund, the Atomic Energy Board Research Fund, and the Muscular Dystrophy Research Foundation of South Africa.

\section{REFERENCES}

Bank, W. J., Di Mauro, S., Bonilla, E., Capuzzi, D. M.' and Rowland, L. P. (1975). A disorder of muscle lipid metabolism and myoglobinuria. Absence of carnitine palmityl transferase. New England Journal of Medicine, 292, 443-449.

Bradley, W. G., Hudgson, P., and Gardner-Medwin, D. (1969). Myopathy associated with abnormal lipid metabolism in skeletal muscle. Lancet, 1, 495-498.

Bradley, W. G., Jenkinson, M., and Park, D. L. (1972). A myopathy associated with lipid storage. Journal of the Neurological Sciences, 16, 137-154.

Bressler, R. (1970). Carnitine and the twins. (Editorial). New England Journal of Medicine, 282, 745-746.

Chanarin, I., Patel, A., Slavin, G., Wills, E. J., Andrews. T. M., and Stewart, G. (1975). Neutral-lipid disease: a new disorder of lipid metabolism. British Medical Journal, 1, 553-555.

Corredor, C., Mansbach, C., and Bressler, R. (1967). Carnitine depletion in the choline-deficient state. Biochimicaet Biophysica Acta, 144, 366-374.
Di Mauro, S. (1976). Quoted in Di Mauro et al. (1975).

Di Mauro, S., and Di Mauro, P. M. M. (1973). Muscle carnitine palmityl transferase deficiency and myoglobinuria. Science 182, 924-931.

Di Mauro, S., Bonilla, E., Lee, C. P., Schotland, D. L., Scarpa, A., Conn, A., and Chance, B. (1975). Luft's disease-further biochemical and ultrastructural studies on skeletal muscle in the second case. Journal of the Neurological Sciences, 27, 217-232.

Di Mauro, S., Scott. C., and Penn, A. S. (1973). Serum carnitine, as index of muscle destruction in man. Archives of Neurology (Chic.), 28, 186-190.

Engel, A. G. (1970). Evolution and content of vacuoles in primary hypokalemic periodic paralysis. Mayo Clinic Proceedings, 45, 774-814.

Engel, A. G., and Angelini, C. (1973). Carnitine deficiency of human muscle with associated lipid storage myopathy: a new syndrome. Science, 179, 899-902.

Engel, A. G., and Dale, A. J. (1968). Autophagic glycogenosis of late onset with mitochondrial abnormalities: Light and electronmicroscopic observations. Mayo Clinic Proceedings, 43, 233-279.

Engel, A. G., and Siekert, R. G. (1972). Lipid storage myopathy responsive to prednisone. Archives of Neurology (Chic.), 27, 174-181.

Engel, A. G., Vick, N. A., and Glueck, C. J. (1970). A skeletal muscle disorder associated with intermittent symptoms and a possible defect of lipid metabolism. New England Journal of Medicine, 282, 697-704.

Fritz, I. B., and Yue, K. T. N. (1963). Long-chain carnitine acyltransferase and the role of acylcarnitine derivatives in the catalytic increase of fatty acid oxidation induced by carnitine. Journal of Lipid Research, 4, 279-280.

Hoppel, C. L., and Tomec, R. J. (1972). Carnitine palmityl transferase: location of two enzymatic activities in rat liver mitochondria. Journal of Biological Chemistry, 247, 832-841.

Isaacs, H., and Heffron, J. J. A. (1974). The syndrome of 'continuous muscle fibre activity' cured: further studies. Journal of Neurology, Neurosurgery, and Psychiatry, 37, 1231-1235.

Isaacs, H., and Muncke, G. (1975). Idiopathic cardiomyopathy and skeletal muscle abnormality. American Heart Journal, 90, 767-773.

Jordans, G. H. W. (1953). Familial occurrence of fat containing vacuoles in leukocytes diagnosed in 2 brothers suffering from dystrophia musculorum progressiva (Erb). Acta Medica Scandinavica, 145, 419-423.

Karpati, G., Carpenter, S., and Engel, A. G. (1974). Carnitine deficiency: a recently recognised and potentially treatable cause of skeletal muscle and liver disease. Neurology (Minneap.), 24, 396.

Lowry, O. H., Rosebrough, N. J., Farr, A. L., and Randall, R. J. (1951). Protein measurements with the Folinphenol reagent. Journal of Biological Chemistry, 193, 265-275. 
Marquis, N. R., and Fritz, I. B. (1965). The distribution of carnitine, acetylcarnitine and carnitine acetyltransferase in rat tissues. Journal of Biological Chemistry, 240, 2193-2196.

Newsholme, E. A., and Start, C. (1973). Regulation of Metabolism, pp. 20-21. Wiley: London.

Pande, S. V. (1975). A mitochondrial carnitine acylcarnitine translocase system. Proceedings of the National Academy of Sciences of the United States of America, 72, 883-887.
Pearson, D. J., Chase, J. F. A., and Tubbs, P. K. (1969). The assay of $(-)$ carnitine and its 0 -acyl-derivatives. In Methods of Enzymology, 14, 612-622. Edited by J. M. Lowenstein. Academic Press: London.

Shy, G. M., Gonatas, N. K., and Perez, M. (1966). Two childhood myopathies with abnormal mitochondria: 1. Megaconial myopathy. 2. Pleoconial myopathy. Brain, 89, 133-158.

Van Dyk, D. H., Greiggs, R. C., Markesberg, W., and Di Mauro, S. (1975). Hereditary carnitine deficiency of muscle. Neurology (Minneap.), 25, 154-159. 